\title{
Living with diabetes: rationale, study design and baseline characteristics for an Australian prospective cohort study
}

\author{
Maria Donald ${ }^{1,3^{*}}$, Jo Dower ${ }^{1}$, Robert Ware ${ }^{1}$, Bryan Mukandi', Sanjoti Parekh and Christopher Bain²
}

\begin{abstract}
Background: Diabetes mellitus is a major global public health threat. In Australia, as elsewhere, it is responsible for a sizeable portion of the overall burden of disease, and significant costs. The psychological and social impact of diabetes on individuals with the disease can be severe, and if not adequately addressed, can lead to the worsening of the overall disease picture. The Living With Diabetes Study aims to contribute to a holistic understanding of the psychological and social aspects of diabetes mellitus.

Methods/Design: The Living With Diabetes Study is a 5-year prospective cohort study, based in Queensland, Australia. The first wave of data, which was collected via a mailed self-report survey, was gathered in 2008, with annual collections thereafter. Measurements include: demographic, lifestyle, health and disease characteristics; quality of life (EQ-5D, ADDQoL); emotional well-being (CES-D, LOT-R, ESSI); disease self-management (PAM); and health-care utilisation and patient-assessed quality of care (PACIC). $29 \%$ of the 14,439 adults who were invited to participate in the study agreed to do so, yielding a sample size of 3,951 people.

Discussion: The data collected by the Living With Diabetes Study provides a good representation of Australians with diabetes to follow over time in order to better understand the natural course of the illness. The study has potential to further illuminate, and give a comprehensive picture of the psychosocial implications of living with diabetes. Data collection is ongoing.
\end{abstract}

\section{Background}

Diabetes mellitus currently affects about 285 million adults worldwide, and this figure is expected to rise to over 400 million adults by 2030 [1]. Based on selfreported data, the prevalence of diagnosed diabetes among Australian adults is $4.4 \%$ [2]. It is possible that the true prevalence is as much as twice that, and likely to increase further given an aging population, more sedentary lifestyles, rising rates of obesity, and a reduction in the rates of diabetes-related mortality [3-5].

The day to day management of diabetes is demanding and can take a heavy psychological and social toll, which may in turn result in poor control of blood glucose levels and an increased risk of complications [6,7]. From the patient's perspective, minimising the burden

\footnotetext{
* Correspondence: m.donald@sph.uq.edu.au

${ }^{1}$ School of Population Health, University of Queensland, Brisbane,

Queensland, Australia Full list of author information is available at the end of the article
}

imposed by diabetes requires an approach that ensures services are integrated, accessible and affordable. They should also be patient-centred, with a strong emphasis on supporting patients' confidence and ability to effectively manage their illness $[8,9]$. To this end, patient reported outcomes such as quality of life and assessments of quality of care are becoming more widely used indicators of health care systems, and are now commonly considered to be critical to the evaluation of the responsiveness of health systems in meeting the needs of their users [10-12].

There is a growing literature on the interaction between various patient-reported outcomes, demographic factors, the self-management of patients with chronic illnesses, and medical outcomes [13,14]. For instance, diabetes patients with higher levels of active self-management enjoy better health outcomes [15,16]; more engaged, informed, confident, and skilled patients are more likely to perform activities that will promote
C Biomed Central 
their own health, and are more likely to have their health care needs met [17]. Fostering patients to take on a meaningful role in their own care is therefore central to improving quality of care and health outcomes.

There is a need to better understand the realities of living with diabetes in order to tailor adequate and appropriate medical and psychosocial interventions $[18,19]$. Many studies have focused on quality of life $[20,21]$, patient activation $[15,16]$, resource utilisation $[22,23]$, or the clinical aspects of diabetes [24,25], but there has not been a concerted effort to simultaneously address all of these in order to gain a more holistic understanding. The Living With Diabetes Study (LWDS) described here extends the focus of previous research into diabetes beyond medical endpoints to encapsulate a broader range of outcomes that contribute to good health and improved quality of life. In particular the LWDS considers: how diabetes affects participants' quality of life, including their mental health and well-being; how satisfied people with diabetes are with the range of health services they use; how people with diabetes manage their condition; and the natural progression of diabetes over time. The findings from the LWDS will provide a more comprehensive picture of the everyday experiences of people living with diabetes and inform health policy planning and service delivery.

\section{Methods/Design}

\section{Study design and sampling scheme}

The LWDS is a 5-year, prospective cohort study being conducted in the state of Queensland, Australia. Data are collected via a mailed self-report questionnaire. Baseline data were collected in 2008 and follow-up measurement waves occur annually.

Participants were recruited from the National Diabetes Services Scheme (NDSS), a government initiative administered by Diabetes Australia that delivers diabetesrelated products at subsidised prices to registrants. In order to register with the NDSS, an individual must receive certification of a diagnosis of diabetes from a doctor or diabetes educator. The NDSS is estimated to cover $80 \%-90 \%$ of the Australian population diagnosed with diabetes [26].

People were eligible to participate in the LWDS if they: were aged 18 years or older; had been diagnosed with type 1 or type 2 diabetes (gestational diabetes was excluded); had a valid Queensland postal address recorded with the NDSS; and indicated on their NDSS registration that they were interested in receiving information about opportunities to participate in research. The final criterion reduced the population available for sampling from 133,851 to 58,504 .

The LWDS sampling scheme oversampled in three areas of policy interest in Queensland: an outer metropolitan area, a new suburban development and a coastal agricultural community. These areas of policy interest contain approximately $7 \%$ of potential participants. While the focus of the LWDS is on documenting the lived experience of diabetes for the entire cohort, differences between these three geographically distinct areas of interest will be provided to the local state health authority for policy and planning purposes. Where appropriate findings from the cohort are weighted to adjust for the oversampling.

The sample size was calculated based on detecting an absolute change in the percentage of participants with poor health-related quality of life of at least $2.5 \%$ between the start and the end of the study. The prevalence of poor health-related quality of life among Queenslanders with diabetes at study initiation was estimated at 30\% [27]. To detect an absolute change of $2.5 \%$ or greater with $90 \%$ power and alpha $=0.05$ we calculated we required 3,457 participants to remain in the study at completion. To achieve this, and assuming $2 \%$ of addresses on the database would be invalid, $40 \%$ of individuals invited to enter the study at baseline would participate, and that each year $10 \%$ of participants would leave the study, we were required to invite 14,350 eligible individuals to participate in the LWDS. All eligible individuals from the three areas of policy interest were invited to participate ( $45 \%$ of all invitees), the remainder of invitees were from the rest of Queensland.

\section{Follow-up, retention and participant tracking}

In order to encourage people with diabetes to participate in the study at baseline, a multi-stage follow-up procedure was used following the initial survey package mail-out. Approximately 3 weeks after the initial mailout, all potential participants were sent a letter designed to thank those people who had returned the survey and prompt those who had not yet returned the questionnaire. Six weeks after the initial mail-out, potential participants who had still not returned a survey were sent a replacement survey package. No further follow-up at baseline was permitted by the NDSS.

In order to minimise non-response for subsequent annual data collection waves, in addition to the thank you/reminder letter and targeted replacement survey mail-outs, targeted reminder letters are sent to those participants who have still not returned a survey 3 weeks after the replacement survey mail-out (i.e. 9 weeks after the initial mail-out). In 2010, due to concerns about the retention rate, targeted reminder telephone calls were also made to those participants who had still not returned a survey after the replacement surveys were sent out.

In order to further maximise retention of cohort participants following recruitment, a range of additional 
strategies and procedures are also used. For the annual follow-up data collections, all participants are sent a small incentive with the questionnaire (e.g. \$1 'scratchit' ticket in 2009 and a pen in 2010), and those who return the questionnaire go into a draw to win one of five $\$ 1,000$ cash prizes. Other strategies include recording the contact details of two alternative contacts for each participant at baseline to assist with tracking; a study website and freecall 1800 number which allows people to update their contact details; biannual study newsletters for participants providing study findings as well as a reminder to update contact details; the inclusion of study synopses in relevant consumer-based organisations' newsletters; and a reminder package, which includes a postage-paid change of address card, sent 4 weeks before the annual survey mail-out.

A participant tracking system involves contacting alternative contacts for participants whose survey packages are 'returned to sender' (RTS) or who are unable to be contacted by telephone during follow-up. If no alternative contacts have been provided an online electronic phonebook is used in an attempt to track the participants. Data linkage to Australia's National Death Index (NDI) occurs annually prior to each data collection to identify deceased LWDS participants.

\section{Response rates}

The participation rate at baseline was $29 \%$ after notified deaths and RTS were omitted $(5.6 \% ; \mathrm{n}=813)$. A study flow chart is presented in Figure 1. The retention rate in 2009 was $88 \%$ after notified deaths and RTS were omitted from calculations. This figure was $86 \%$ for the 2010 data collection.

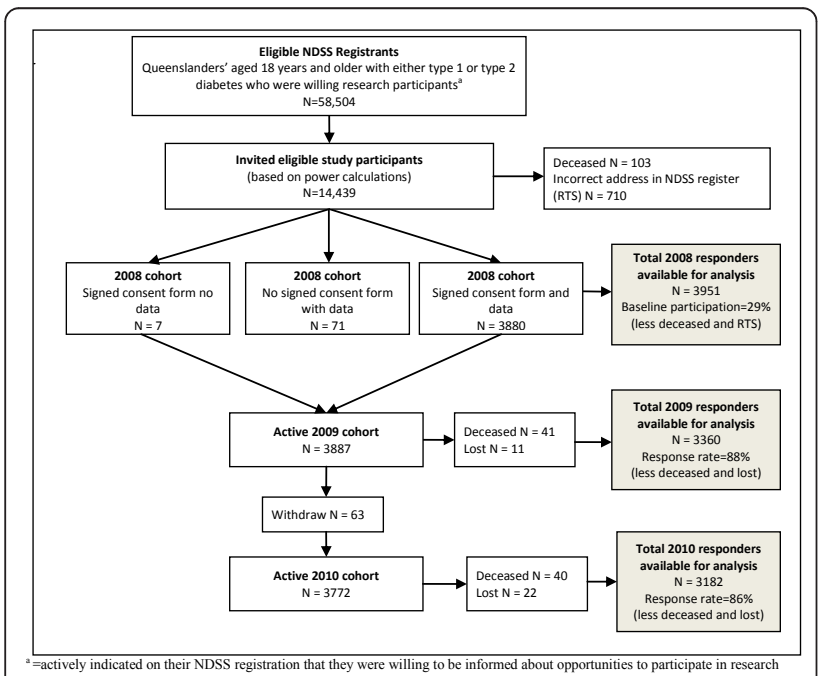

Figure 1 Flow chart of study design and response rates.

\section{Participants versus non-participants}

A previous analysis, using aggregated data provided by NDSS, compared the study's participants with non-participants, as well as the study's participants with all other NDSS registrants in Queensland including those who on their NDSS registration form did not consent to research participation [28]. The findings showed that participants were more likely than non-participants to be aged 50 to 69 years and to be non-indigenous Australians (see Table 1). The analyses comparing study participants with the broader population of NDSS registrants showed that the study's participants were more

Table 1 Comparison between LWDS participants and non-participants (adapted from David, Ware, Donald et al., 2011)

\begin{tabular}{|c|c|c|c|}
\hline & Participants & $\begin{array}{c}\text { Non- } \\
\text { participants }\end{array}$ & OR $(95 \% \mathrm{Cl})$ \\
\hline & $\mathrm{N}=3,951$ & $N=10,488$ & \\
\hline \multicolumn{4}{|l|}{ Sex } \\
\hline Male & $\begin{array}{c}2,176 \\
(55.1 \%)\end{array}$ & $5,885(56.1 \%)$ & 1 \\
\hline Female & $\begin{array}{c}1,775 \\
(44.9 \%)\end{array}$ & 4,603 (43.9\%) & $\begin{array}{c}1.01(0.93- \\
1.10)\end{array}$ \\
\hline \multicolumn{4}{|l|}{ Age } \\
\hline $18-49$ & $618(15.6 \%)$ & $2,246(21.4 \%)$ & $\begin{array}{c}0.67(0.60- \\
0.75)\end{array}$ \\
\hline $50-69$ & $\begin{array}{l}2,375 \\
(60.1 \%)\end{array}$ & 5,649 (53.9\%) & 1 \\
\hline $70+$ & $958(24.3 \%)$ & $2,593(24.7 \%)$ & $\begin{array}{c}0.88(0.80- \\
0.97)\end{array}$ \\
\hline \multicolumn{4}{|l|}{ Diabetes Status } \\
\hline Type 2 No Insulin & $\begin{array}{c}3,023 \\
(76.5 \%)\end{array}$ & $8,024(76.5 \%)$ & 1 \\
\hline Type 2 Insulin & $738(18.7 \%)$ & 1,986 (18.9\%) & $\begin{array}{c}0.97(0.87- \\
1.08)\end{array}$ \\
\hline Type 1 Insulin & $190(4.8 \%)$ & $478(4.6 \%)$ & $\begin{array}{c}1.11(0.91- \\
1.34)\end{array}$ \\
\hline \multicolumn{4}{|l|}{ Registration Year } \\
\hline $2001-2003$ & $\begin{array}{c}1,303 \\
(38.0 \%)\end{array}$ & $3,422(37.0 \%)$ & 1 \\
\hline $2004-2005$ & $805(23.4 \%)$ & $2,239(24.2 \%)$ & $\begin{array}{c}0.96(0.85- \\
1.07)\end{array}$ \\
\hline $2006-2008$ & $\begin{array}{c}1,325 \\
(38.6 \%)\end{array}$ & $3,580(38.8 \%)$ & $\begin{array}{c}1.01(0.92- \\
1.12)\end{array}$ \\
\hline \multicolumn{4}{|l|}{$\begin{array}{l}\text { Socioeconomic } \\
\text { status }\end{array}$} \\
\hline Low & $830(21.0 \%)$ & $2,491(23.8 \%)$ & 1 \\
\hline Middle & $\begin{array}{c}1,543 \\
(39.1 \%)\end{array}$ & $3,883(37.1 \%)$ & $\begin{array}{l}1.13(1.01- \\
1.27)\end{array}$ \\
\hline High & $\begin{array}{c}1,572 \\
(39.9 \%)\end{array}$ & 4,100 (39.1\%) & $\begin{array}{c}1.11(0.99- \\
1.24)\end{array}$ \\
\hline \multicolumn{4}{|l|}{ Indigenous } \\
\hline No & $\begin{array}{c}3,838 \\
(97.2 \%)\end{array}$ & 9,969 (95.1\%) & 1 \\
\hline Yes & $113(2.8 \%)$ & $519(4.9 \%)$ & $\begin{array}{l}0.57(0.45- \\
0.71)\end{array}$ \\
\hline
\end{tabular}


likely than NDSS registrants to be male, aged 50-69 years, be recently registered with the NDSS scheme and be non-indigenous Australians. In addition, there was an underrepresentation of patients with type 1 diabetes among study participants (4.8\%) compared to NDSS registrants $(14.5 \%)$.

\section{Measures and instruments}

The study collects information on a range of issues, including the primary outcomes of interest-quality of life and quality of care. Clinical outcomes such as the onset of diabetes complications and $\mathrm{HbA} 1 \mathrm{c}$ are also measured. An overview of the components of the survey is provided in Table 2. Information relating to 347 primary variables was collected in the 2008 LWDS questionnaire. A copy of the questionnaire is available from the authors on request or can be downloaded from the study's website at http://www.lwds.org.au.

The NDI will be used to identify premature deaths, and cause of death data will be accessed at the completion of the study. In addition, a proposed data linkage to Australia's Medical Benefits Scheme (MBS) and Pharmaceutical Benefits Scheme (PBS) has also gained ethics approval and will provide information about individual participant's use of government subsidised health services and medications. Access to these administrative data will not only provide information to verify selfreport health care utilisation data, but will also allow for more detailed examination of the timing of services and health outcomes.

\section{Main outcomes of interest \\ Health-related quality of life}

The EQ-5D, developed by the EuroQoL Group, is widely used in clinical trials, observational studies and health surveys, and has been translated into most major languages $[35,48]$. The measure includes a descriptive system comprising five dimensions and a visual analogue scale. The dimensions measured are: mobility, self-care, usual activities, pain/discomfort and anxiety/depression. To complete the visual analogue scale respondents are asked to rate their current health status on a scale from 0 to 100 , where 0 is the worst imaginable health and 100 is the best imaginable health. The EQ-5D also provides a preference-based utility index where responses are converted to a single weighted score. This gives a

Table 2 Summary of main variables collected

\begin{tabular}{|c|c|c|}
\hline Section & Examples of Variables & Measures and Standardised Scales \\
\hline $\begin{array}{l}\text { A: Disease- } \\
\text { related factors }\end{array}$ & $\begin{array}{l}\text { Type of diabetes and Disease duration } \\
\text { Glycaemic control, Treatment type, Diabetes Complications \& } \\
\text { Co-morbidity }\end{array}$ & Diabetes type verified using NDSS data \\
\hline $\begin{array}{l}\text { B: Health and } \\
\text { Lifestyle }\end{array}$ & $\begin{array}{l}\text { Nutrition } \\
\text { Smoking status } \\
\text { Alcohol consumption } \\
\text { Physical activity } \\
\text { Height, Weight, } \\
\text { Sleep patterns (2010 only) }\end{array}$ & $\begin{array}{l}\text { Dietary Guidelines for Australian Adults [29] } \\
\text { National Drug Strategy Household Survey [30] } \\
\text { Frequency-quantity measure\# \& National Health and Medical } \\
\text { Research Council Guidelines [31]. } \\
\text { Active Australia Survey [32] \& National Physical Activity } \\
\text { Guidelines for Australians [33] } \\
\text { Body Mass Index adapted from WHO [34] }\end{array}$ \\
\hline C: Quality of Life & $\begin{array}{l}\text { Health related quality of life } \\
\text { Diabetes-specific quality of life }\end{array}$ & $\begin{array}{l}\text { Euroqol EQ-5D [35] } \\
\text { Audit of Diabetes Dependant Quality of Life (ADDQoL) [36,37] }\end{array}$ \\
\hline $\begin{array}{l}\text { D: Disease } \\
\text { management }\end{array}$ & $\begin{array}{l}\text { Self-management } \\
\text { Compliance with providers recommendations } \\
\text { Disease management resources (2010 only) }\end{array}$ & $\begin{array}{l}\text { Patient Activation Measure (PAM) [38] } \\
\text { Summary of Diabetes Self-Care Activities (Modified) [39] } \\
\text { Chronic Illness Resources Survey (CIRS) [40] }\end{array}$ \\
\hline $\begin{array}{l}\text { E: Health care } \\
\text { utilisation }\end{array}$ & $\begin{array}{l}\text { Primary care visits } \\
\text { Allied health visits } \\
\text { Emergency department visits } \\
\text { Hospitalisations and reasons }\end{array}$ & \\
\hline F: Quality of care & $\begin{array}{l}\text { Patient-assessed quality of care } \\
\text { Satisfaction with care (access, coordination) } \\
\text { Practitioner compliance with guidelines }\end{array}$ & $\begin{array}{l}\text { Patient Assessment of Chronic Illness Care (PACIC) [41] } \\
\text { Australian Diabetes Management in General Practice } \\
\text { guidelines [42] }\end{array}$ \\
\hline $\begin{array}{l}\text { G: Emotional } \\
\text { well-being }\end{array}$ & $\begin{array}{l}\text { Depressive symptomatology } \\
\text { Stressful life events } \\
\text { Optimism }(2009,2010) \\
\text { Social Support }(2009,2010)\end{array}$ & $\begin{array}{l}\text { Centre for Epidemiological Studies: Depression Scale (CES-D) } \\
\text { [43] } \\
\text { Life Orientation Test - Revised (LOT-R) [44] } \\
\text { ENRICHED Social Support Inventory (ESSI) [45] }\end{array}$ \\
\hline $\begin{array}{l}\text { H: Socio- } \\
\text { demographics }\end{array}$ & $\begin{array}{l}\text { Age, Sex, Marital status, Ethnicity, Employment status, } \\
\text { Educational status \& Household income } \\
\text { Private health insurance; Health concession cards, Out of pocket } \\
\text { health costs }\end{array}$ & Derived from Australia's National Health Survey questions [46] \\
\hline
\end{tabular}

\footnotetext{
\# The frequency-quantity method used to measure alcohol consumption in the LWDS is a relatively conservative estimate of high risk alcohol consumption [47]
} 
possible 243 health states, 245 when unconscious and dead are included. An EQ-5D score of 1 corresponds to perfect health; 0 to indifference between death and living; and, any numbers less than 0 to a state where death is preferred.

\section{Diabetes-specific quality of life}

The ADDQoL consists of two overview items; one measures generic overall quality of life and the second measures the specific impact of diabetes on quality of life. A further 19 domains concerned with the impact of diabetes on specific aspects of life are also measured. Participants are asked to rate the impact of diabetes on each domain and the importance of the domain for their quality of life. These two scores are then multiplied to yield a weighted impact score for each domain (range -9 to +3 ). Finally, an average weighted impact score is then calculated for the entire scale.

\section{Quality of care}

Respondents completed the Patient Assessment of Chronic Illness Care (PACIC), which measures the extent to which patients report receiving care that is consistent with the dimensions of the Chronic Care Model (CCM) [49]. The PACIC consists of 20 items with each item scored using a five point scale, ranging from 1 being none of the time to 5 being always. The items aggregate into five sub-scales that align with the dimensions of the CCM: patient activation, delivery system design/decision support, goal setting/tailoring, problem solving/contextual, and follow-up/coordination. Patient activation assesses the extent to which the patient was motivated and supported by the physician to initiate changes. Delivery system design/decision support assesses the degree to which the patient was supported (e.g. by information sheets), and how satisfied the patient was with the organisation of that care. Goal setting/tailoring assesses to what extent general instructions and suggestions were adapted to the patient's personal situation. Problem solving/contextual addresses how the physician dealt with problems which interfered with achieving predefined goals. Finally, follow-up/coordination addresses how frequently and consistently the care process was followed-up. Each sub-scale is scored by averaging across the items within that sub-scale, with an overall PACIC score obtained by averaging across all 20 items. Higher scores indicate higher quality care.

To provide another measure of quality of care, participants completed a series of purpose-designed quality indicators based on specific aspects of care recommended in the Australian Diabetes Management in General Practice guidelines [42], by indicating whether a member of their medical team had undertaken the care activity in the preceding 12 months.

\section{Ethics}

Ethics approval for the study was granted by the University of Queensland's Behavioural and Social Sciences Ethical Review Committee. Written informed consent was obtained from all individuals followed over time. Consent forms are removed from returned surveys and stored in a locked filing cabinet.

\section{Data management and statistical analyses}

After entry, data is both manually and statistically checked during the data-cleaning process. Data are verified against the returned surveys when necessary. Electronic scanned copies of all original surveys are kept on file in a password-protected data file while hard copies are destroyed.

Initially, descriptive statistics are calculated for all variables. Where appropriate proportions are weighted to adjust for the oversampling, and unweighted sample sizes and weighted percentages are reported. Change over the follow-up period will be assessed using generalised estimating equations (GEE), which will allow for the best use of all data collected as GEEs do not require balanced data sets. Using GEEs will allow the data of all individual participants to be included in analyses, irrespective of the level of questionnaire completion.

The exact final method of analysis will be outcomedependent. However, as a rule all associations will be assessed in the following stepwise manner: (a) univariate analysis: only adding the specific independent variable to the model; (b) a multivariate model to establish the significant associations; (c) adjusting for age, gender and socio-economic indicators to explore potential confounding factors; and (d) the addition of potential effectmodifiers by using interaction terms wherever necessary.

\section{Baseline characteristics of the sample}

Baseline socio-demographic characteristics of the sample are presented in Table 3 for the purpose of assessing the potential generalisability of the findings to Australians with diabetes. Fifty-five percent of the research participants were male. Participants' age ranged from 18 to 94 years. The overall mean age was 61.4 years $(S D=12.1)$. Educational status varied; $13.4 \%$ of participants had completed university study, while almost half (46.5\%) reported education to grade 10 (i.e. junior certificate) or lower. A large proportion of the sample (44.5\%) was retired. Only $1.8 \%$ of the study population reported being of Indigenous origin. Almost two thirds of participants live in households earning less than $\$ 60,000$ (AUD) per annum, while $30.6 \%$ of LWDS households earned less than $\$ 20,000$ (AUD) per annum. 62.0\% of LWDS participants reported that they hold a health care card which provides access to subsidised health care. 
Table 3 Baseline socio-demographic characteristics

\begin{tabular}{lcc}
\hline Socio-demographic characteristic & $\begin{array}{c}\text { All Persons } \\
\mathbf{n}=3951\end{array}$ & $\%$ \\
\hline Gender & & \\
$\quad$ Male & 2175 & $55.1 \%$ \\
$\quad$ Female & 1776 & $44.9 \%$ \\
Age & & \\
$\quad$ 18-44 year & 343 & $8.7 \%$ \\
$\quad$ 45-59 year & 1204 & $30.5 \%$ \\
$\quad 60-74$ year & 1921 & $48.6 \%$ \\
$\quad 75+$ year & 483 & $12.2 \%$ \\
Education Level & & \\
$\quad$ University degree & 516 & $13.4 \%$ \\
$\quad$ Certificate/diploma/trade & 1044 & $27.2 \%$ \\
$\quad$ Senior high school & 495 & $12.9 \%$ \\
$\quad$ Year 10 and below & 1789 & $46.5 \%$ \\
Employment Status & & \\
$\quad$ Full time/part time/self-employed & 1521 & $39.1 \%$ \\
$\quad$ Home duties/carer/volunteer & 241 & $6.2 \%$ \\
$\quad$ Unemployed (but able to work) & 94 & $2.4 \%$ \\
$\quad$ Retired & 1729 & $44.5 \%$ \\
$\quad$ Unable to work & 301 & $7.8 \%$ \\
Married or living as married & 2766 & $70.8 \%$ \\
English speaking background & 3750 & $98.2 \%$ \\
Indigenous Australian & 70 & $1.8 \%$ \\
Household annual income $<$ \$60,000(AUD) & 2540 & $73.7 \%$ \\
Health concession cards (yes) & 2394 & $62.0 \%$ \\
\hline
\end{tabular}

Baseline medical and lifestyle characteristics of the LWDS sample are summarised in Table 4. The median duration of time since receiving a diagnosis of diabetes was 5 years and the mean was 6 years (range: less than 1 year to 50 years). Overall, $83 \%$ of participants reported being diagnosed within the past 8 years, with more than half (69.7\%) managing their diabetes with oral hypoglycaemic drugs. Approximately one out of five participants was insulin requiring. Erectile dysfunction was the most commonly reported diabetes complication among men (41.4\%), followed by diabetes related eye disease (e.g. retinopathy, cataracts, glaucoma), which was the highest among women. Overall, one in ten LWDS participants smoked daily. More than four out of five participants were overweight, with half being obese or morbidly obese.

Given established differences between males and females on several factors with likely implications for intervention, Table 4 also presents medical and lifestyle characteristics stratified by gender. Sub-group analysis by gender showed no significant differences for the diabetes-specific characteristics such as type of diabetes, length of diagnosis or HbA1c levels. However, gender specific differences were observed for several diabetes complications: including foot ulcers, cardiovascular
Table 4 Baseline medical and lifestyle factors

\begin{tabular}{|c|c|c|c|c|}
\hline Medical or lifestyle factor & $\begin{array}{c}\text { All } \\
\text { Persons }\end{array}$ & Males & Females & $\begin{array}{c}p- \\
\text { value }\end{array}$ \\
\hline \multicolumn{5}{|l|}{ Medical } \\
\hline \multicolumn{5}{|l|}{ Type of diabetes } \\
\hline Type 1 & $4.8 \%$ & $4.5 \%$ & $5.2 \%$ & 0.256 \\
\hline Type 2 & $95.2 \%$ & $95.5 \%$ & $94.8 \%$ & \\
\hline \multicolumn{5}{|l|}{ Length of diagnosis } \\
\hline 2 years or less & $25.5 \%$ & $25.4 \%$ & $25.6 \%$ & 0.298 \\
\hline 3 to 8 years ago & $57.5 \%$ & $56.7 \%$ & $58.3 \%$ & \\
\hline More than 8 years ago & $17.0 \%$ & $17.8 \%$ & $16.1 \%$ & \\
\hline Diet only treated diabetes & $4.1 \%$ & $\begin{array}{c}3.8 \% \\
\%\end{array}$ & $4.4 \%$ & 0.372 \\
\hline $\begin{array}{l}\text { Current oral hypoglycaemic } \\
\text { agents }\end{array}$ & $69.7 \%$ & $71.8 \%$ & $67.7 \%$ & 0.005 \\
\hline Insulin requiring & $21.6 \%$ & $22.7 \%$ & $20.2 \%$ & 0.055 \\
\hline \multicolumn{5}{|l|}{ HbA1c Levels } \\
\hline $7.0 \%$ or lower & $48.7 \%$ & $48.2 \%$ & $49.2 \%$ & \\
\hline $7.1 \%-8.0 \%$ & $21.7 \%$ & $22.4 \%$ & $20.8 \%$ & 0.070 \\
\hline Over $8.0 \%$ & $14.3 \%$ & $15.1 \%$ & $13.3 \%$ & \\
\hline Don't know & $15.4 \%$ & $14.3 \%$ & $16.7 \%$ & \\
\hline Lipid-lowering agents & $52.1 \%$ & $52.8 \%$ & $51.0 \%$ & 0.224 \\
\hline Antihypertensive therapy & $57.3 \%$ & $57.9 \%$ & $56.6 \%$ & 0.412 \\
\hline Current depression & $38.5 \%$ & $35.7 \%$ & $41.8 \%$ & $<0.001$ \\
\hline \multicolumn{5}{|l|}{ Diabetes Complications } \\
\hline Eye disease & $23.3 \%$ & $23.7 \%$ & $22.8 \%$ & 0.500 \\
\hline Kidney disease & $6.2 \%$ & $6.8 \%$ & $5.5 \%$ & 0.090 \\
\hline Neuropathy & $8.8 \%$ & $9.4 \%$ & $8.2 \%$ & 0.192 \\
\hline Erectile dysfunction & - & $41.4 \%$ & - & - \\
\hline Foot ulcers & $2.1 \%$ & $2.6 \%$ & $1.5 \%$ & 0.017 \\
\hline Heart disease $^{a}$ & $15.4 \%$ & $19.4 \%$ & $10.6 \%$ & $<0.001$ \\
\hline $\begin{array}{l}\text { Stroke or transient ischaemic } \\
\text { attack }\end{array}$ & $5.1 \%$ & $6.0 \%$ & $3.9 \%$ & 0.003 \\
\hline \multicolumn{5}{|l|}{ Behavioural lifestyle } \\
\hline Inadequate fruit consumption & $39.5 \%$ & $43.4 \%$ & $34.8 \%$ & $<0.001$ \\
\hline $\begin{array}{l}\text { Inadequate vegetable } \\
\text { consumption }\end{array}$ & $87.2 \%$ & $90.1 \%$ & $83.6 \%$ & $<0.001$ \\
\hline Insufficient physical activity ${ }^{\mathrm{b}}$ & $50.7 \%$ & $45.2 \%$ & $57.3 \%$ & $<0.001$ \\
\hline Current smokers & $10.5 \%$ & $10.7 \%$ & $10.2 \%$ & 0.619 \\
\hline Risky alcohol consumers & $6.6 \%$ & $8.5 \%$ & $4.6 \%$ & $<0.001$ \\
\hline \multicolumn{5}{|l|}{$\mathrm{BMI}\left(\right.$ mean $\left.=31.1 \pm 6.9 \mathrm{~kg} / \mathrm{m}^{2}\right)$} \\
\hline Underweight & $0.5 \%$ & $0.2 \%$ & $0.9 \%$ & $<0.001$ \\
\hline Normal & $16.4 \%$ & $15.7 \%$ & $17.3 \%$ & \\
\hline Overweight & $33.3 \%$ & $39.2 \%$ & $25.9 \%$ & \\
\hline Obese or morbidly obese & $49.7 \%$ & $44.9 \%$ & $55.8 \%$ & \\
\hline
\end{tabular}

a includes heart disease, angina, heart attack, irregular heart rhythm, missed heart beats or blocked artery in the heart

${ }^{b}$ insufficient for health benefit is defined as less than 150 min of at least moderate-intensity physical activity over at least five sessions in the previous week (18-75 years only)

disease and stroke. In addition, females were more likely than males to report co-morbid depressive symptomatology. With the exception of current smokers, statistically significant gender differences were observed for 
each of the health risk behaviours, including body mass index (BMI).

\section{Discussion}

This paper describes the study rationale and procedures for the LWDS and reports the baseline characteristics of a cohort of 3951 people with diabetes. The approach of the LWDS differs from other national and international studies of diabetes in its focus on examining the natural trajectory of diabetes and its treatment from a psychosocial perspective. It is hoped that this will lead to a greater understanding of how to improve the life and quality of care of people with diabetes. The large cohort will allow for the undertaking of multivariate statistical analyses, and the longitudinal nature of the data enables the investigation of temporal effects.

Wherever possible standardised scales and questions were used in the LWDS questionnaire to measure the domains of interest. We relied on previous health services research and psychosocial research to select measures sensitive to change and with adequate face, content and construct validity. The importance of distinguishing between health-related quality of life and disease-specific quality of life has been highlighted by previous researchers $[11,50]$. On this basis, both are measured in the LWDS. Health-related quality of life measures a patient's symptoms and functioning. The EQ-5D is one of the most widely used preference-based measures of health-related quality of life [51]. Diseasespecific quality of life, which captures the broader multidimensional, subjective and dynamic features of quality of life, relates more specifically to a person's perception of how a specific disease has impacted on their life [52]. Disease-specific measurement instruments include those aspects of life considered to be the most important by patients and clinicians resulting in a more detailed assessment of the issues and concerns relevant to the specific disease, its treatments and complications $[13,37,53]$. Several recent reviews of diabetes-specific quality of life instruments conclude that there is good evidence that the ADDQoL, used in the LWDS, is a reliable measure of disease-specific quality of life with good face and content validity [52-55]. A recent assessment of 37 measures of patient-assessed quality of care designed for use with people with chronic illness found the PACIC, used in the LWDS, to be the most appropriate as determined by its psychometric properties and perceived applicability and relevance [41]. The inclusion of these self-reported patient assessments of quality of life and quality of care will allow for the reliable assessment of the impact that the progression of diabetes has on these important health and well-being outcomes.

The LWDS study has the inherent limitations of selfreport surveys. The reliability and validity of self-report health measures varies across behaviours and outcomes. Self-reported health service utilisation data is subject to recall bias and underreporting, especially for older adults and frequent users of primary care [56,57]. Cross-referencing the self-report service utilisation data with MBS data will improve the reliability and validity of this information. Self-report data on health information, such as co-morbidities, has been found to be of variable quality, but is generally satisfactory for well-known conditions [58,59]. Previous research has found a positive, albeit weak, correlation between self-reported $\mathrm{HbA} 1 \mathrm{c}$ values and medical record data [60]. Self-report of treatment types including oral agents and insulin use are generally valid [61].

While recruitment at baseline was slightly lower than anticipated, it is similar to that of other studies of this nature [62] and is consistent with research showing that participation rates in large cohort studies appear to be decreasing. It is estimated that rates have declined from about $80 \%$ to $30 \%$ or $40 \%$ over the past several decades [63]. Effective participant retention is vital to the success of the LWDS and we have instituted an anti-attrition strategy to ensure as many cohort members as possible remain in the study. Past research suggests that the attrition in follow-up for postal surveys can be decreased by the provision of a monetary incentive such as a lottery ticket or a prize [64], with the magnitude less important than an incentive per se [65]. Although losses to follow-up are inevitable, the study's comprehensive retention strategy to date has been successful in limiting participant drop-out. However, it is possible that those individuals whose health deteriorates more markedly over time will discontinue study participation, biasing findings towards healthier participants.

Use of a national disease register with high coverage of the target population in the recruitment process has been effective for enrolling a large representative sample of people with diabetes, covering a broad range of socio-demographic and clinical characteristics. Specifically, the proportion of males was consistent with estimates provided by Australia's National Health Survey that $56 \%$ of Australians with diabetes are male [2]. The large proportion of LWDS participants with low levels of educational attainment is not unexpected given the older age distribution of the sample. Similarly, it is unsurprising that a large proportion of the sample (44.3\%) was retired and one in 15 reported being unable to work.

In 2005-06 the average gross annual household income in Australia was around \$68,000 (AUD) [66]. While it is difficult to make direct comparisons based on the income brackets used in the LWDS, the finding that $73.7 \%$ of participants live in households earning less than $\$ 60,000$ (AUD) per annum indicates that overall 
the sample are more economically disadvantaged than the general population of Australians. This differential is consistent with what would be expected given the previously reported relationship between low socio-economic status and prevalence of diabetes $[67,68]$ as well as the high levels of retirement among the LWDS participants.

A similar pattern holds for health concession cards. In Australia low income is one of the criteria for eligibility for a government health concession card. Possession of the card can significantly reduce the out-of-pocket expenses for consumers through subsidised medical care, hospital treatment and some medications. Australia's 2004-05 National Health Survey reported 35\% of persons 15 years and over were covered by a government health card, a figure considerably lower than the $62.0 \%$ of LWDS participants reporting that they hold a health care card. The higher LWDS proportion will most likely be accounted for by the older age and poorer health status of people with diabetes.

Another area in which the study is not representative of the general population relates to the proportion of Indigenous Australians. Research shows that diabetes is more common among Indigenous Australians [69] than among their non-Indigenous counterparts. However, with census data showing that $2.5 \%$ of the Australian population report an Indigenous background [70] and only $1.8 \%$ of the study population reporting that they are of Indigenous origin the LWDS cannot be generalised to this population.

Less than one in 20 LWDS participants relied on diet alone as the treatment pathway for their diabetes. Previous researchers have suggested that people managing their diabetes through diet and exercise alone may not have a high level of need for the NDSS's services and would therefore be less likely to register with the scheme [26]. Our findings support this assumption. Less than $5 \%$ of the LWDS sample reported having a diagnosis of type 1 diabetes. The true prevalence of type 1 diabetes in Australia is estimated to be approximately $10 \%$ [2]. The underrepresentation of patients with type 1 diabetes is attributed to the lower likelihood of NDSS registrants with type 1 diabetes consenting to participate in research as there is not systematic updating of research consent status at the age of 18 among those registered as a child [28]. We acknowledge this as a weakness of the LWDS with implications for the generalisability of the study to people with type 1 diabetes. Future analyses of the data will stratify by diabetes type.

On the other hand, the diabetes complications reported by the LWDS participants at baseline were very much in keeping with the available Australian statistics for the Australian diabetic population as a whole [71]. For example, $2.1 \%$ of respondents reported having foot ulcers, with the available comparable figure for the entire Australian diabetic population also 2.1\%. Additionally, $6.2 \%$ of the sample, compared to $6.3 \%$ of the Australian diabetic population, reported kidney disease; $5.1 \%$ of the sample compared to $5.0 \%$ of the Australian diabetic population reported having had a stroke; $8.8 \%$ of the sample versus $8.6 \%$ of the Australian diabetic population reported neuropathy; and $41.4 \%$ of men on the study reported erectile dysfunction as a complication, while $30.2 \%$ of the general male diabetic population had the same complaint. The discrepancy for erectile dysfunction may stem from the differing data collection methods used to obtain the estimates.

Lifestyle changes constitute an important aspect of the management of diabetes, in particular type 2 diabetes. For example, obesity in those with type 2 diabetes complicates management of the disease by increasing insulin resistance and with that, blood glucose concentrations. This however, is reversible, such that weight loss of just $5 \%$ of body weight may improve insulin sensitivity and glycaemic control $[72,73]$. Research undertaken with US adults found that those with diabetes were more likely to be physically inactive (61\%) than those without diabetes (42\%) [74]. Recent comparable physical activity rates for the Australian general population are not available. We can however compare the LWDS with the Australian Diabetes, Obesity and Lifestyle Study (AusDiab) conducted in1999 -2000 which found that $59.3 \%$ of Australians with diabetes were insufficiently active [75], which is higher than the $50.7 \%$ found for the LWDS sample. Recent suggestions of a trend towards increased levels of physical activity among Australians may explain the difference [76]. It is well established that on average people with diabetes are more likely to be overweight than people without diabetes. Both the LWDS and the AusDiab study [71] found that approximately four out of five diabetic patients are overweight or obese. The baseline estimates for health risk behaviours for participants of the LWDS suggest that there is considerable scope for behavioural lifestyle modification among Australians with diabetes.

The wide range of information collected from the LWDS participants allows for an in-depth exploration of the multidimensional nature of diabetes. The availability of longitudinal data allows the LWDS to contribute towards a deeper understanding of the dynamics of living with diabetes; and to build complex psychosocial models of the determinants of disease progression, quality of life and models of patients' assessments of the quality of their care. This will allow for the identification of key targets for intervention strategies, and will contribute to public health policy, especially as it relates to resource allocation and planning. 


\section{Acknowledgements and funding}

The Living with Diabetes Study is funded by Queensland Health.

\section{Author details}

${ }^{1}$ School of Population Health, University of Queensland, Brisbane, Queensland, Australia. ${ }^{2}$ Genetics and Population Health Division, Queensland Institute of Medical Research, Brisbane, Queensland, Australia. ${ }^{3}$ University of Queensland, Room 119, Level 2, Public Health Building, Herston, Brisbane, Qld 4006, Australia.

\section{Authors' contributions}

MD made a substantial contribution to the conception and design of the study as well as interpretation of the data and was involved in drafting the manuscript. JD contributed to the interpretation of the data and was involved in drafting the manuscript. RW supervised the statistical analyses and was involved in drafting the manuscript. BM contributed to interpretation of the data and was involved in drafting the manuscript. SP performed the statistical analysis and was involved in drafting the manuscript. CB contributed to the conception of the study and was involved in revising the intellectual content of the manuscript. All authors read and approved the final manuscript.

\section{Competing interests}

MD, JD, RW, BM and SP all had financial support from Queensland Health.

Received: 21 November 2011 Accepted: 5 January 2012

Published: 5 January 2012

\section{References}

1. Shaw JE, Sicree RA, Zimmet PZ: Global estimates of the prevalence of diabetes for 2010 and 2030. Diabetes Res Clin Pract 2010, 87(1):4-14.

2. AlHW: Diabetes prevalence in Australia: Detailed estimates for 2007-08. Diabetes Series No 17 Cat no CVD 56 Canberra: Australian Institute of Health and Welfare; 2011

3. Cameron AJ, Welborn TA, Zimmet PZ, Dunstan DW, Owen N, Salmon J, Dalton M, Jolley D, Shaw JE: Overweight and obesity in Australia: the 1999-2000 Australian Diabetes, Obesity and Lifestyle Study (AusDiab). Medical Journal of Australia 2003, 178(9):427-432.

4. Magliano DJ, Peeters A, Vos T, Sicree R, Shaw J, Sindall C, Haby M, Begg SJ, Zimmet PZ: Projecting the burden of diabetes in Australiawhat is the size of the matter? Aust New Zealand J Public Health 2009, 33(6):540-543

5. Chittleborough CR, Grant JF, Phillips PJ, Taylor AW: The increasing prevalence of diabetes in South Australia: the relationship with population ageing and obesity. Public Health 2007, 121(2):92-99.

6. Wandell PE, Brorsson B, Aberg H: Psychic and socioeconomic consequences with diabetes compared to other chronic conditions. Scand J Public Health 1997, 25(1):39-43.

7. Rubin RR, Peyrot M: Psychological issues and treatments for people with diabetes. J Clin Psychol 2001, 57(4):457-478.

8. Glasgow RE, Funnell MM, Bonomi AE, Davis C, Beckham V, Wagner EH: Selfmanagement aspects of the improving chronic illness care breakthrough series: implementation with diabetes and heart failure teams. Ann Behav Med 2002, 24:80-87.

9. Bodenheimer T, Wagner EH, Grumbach K: Improving primary care for patients with chronic illness: the chronic care model, Part 2. JAMA 2002, 288(15):1909-1914

10. Devlin N, Appleby J: Getting the most out of PROMS: putting health outcomes at the heart of NHS decision-making. London, United Kingdom: The King's Fund; 2010.

11. Sundaram M, Kavookjian J, Patrick JH: Health-related quality of life and quality of life in type 2 diabetes: relationships in a cross-sectional study. The Patient: Patient-Centered Outcomes Res 2009, 2(2):121-133.

12. Rosenthal GE, Shannon SE: The Use of patient perceptions in the evaluation of health-care delivery systems. Med Care 1997, 35(11) NS58-NS68.

13. Rubin RR, Peyrot M: Quality of life and diabetes. Diabetes Metab Res Rev 1999, 15(3):205-218.

14. Leplege A, Hunt S: The problem of quality of life in medicine. JAMA 1997, 278(1):47-50.
15. Hibbard JH, Mahoney ER, Stock R, Tusler M: Do increases in patient activation result in improved self-management behaviors? Health Serv Res 2007, 42(4):1443-1463.

16. Mosen DM, Schmittdiel J, Hibbard JH, Sobel D, Remmers C, Bellows J: Is patient activation associated with outcomes of care for adults with chronic conditions? J Ambulatory Care Manage 2007, 30(1):21-29.

17. Hibbard JH, Cunningham J: HOW engaged are Consumers in their Health and Health Care, and Why Does it Matter? October. Washington: Center for Studying Health System Change; 20088.

18. Griffiths F, Anto N, Chow E, Manazar U, Van Royen P, Bastiaens H: Understanding the diversity and dynamics of living with diabetes: a feasibility study focusing on the case. Chronic IIIn 2007, 3(1):29-45.

19. Paterson BL, Thorne S, Dewis M: Adapting to and managing diabetes. J Nurs Scholarsh 1998, 30(1):57-62.

20. Koopmanschap M: Coping with type II diabetes: the patient's perspective. Diabetologia 2002, 45:S18-S22.

21. Wexler D, Grant R, Wittenberg E, Bosch J, Cagliero E, Delahanty L: Correlates of health-related quality of life in type 2 diabetes. Diabetologia 2006, 49:1489-1497.

22. Ringborg A, Martinell M, Stålhammar J, Yin DD, Lindgren P: Resource use and costs of type 2 diabetes in Sweden-estimates from populationbased register data. Int J Clin Pract 2008, 62(5):708-716.

23. Tomlin AM, Tilyard MW, Dovey SM, Dawson AG: Hospital admissions in diabetic and non-diabetic patients: a case-control study. Diabetes Res Clin Pract 2006, 73(3):260-267.

24. Diabetes Prevention Program Research Group: Reduction in the incidence of type 2 diabetes with lifestyle intervention or metformin. $N$ Engl I Med 2002, 346(6):393-403

25. Stratton IM, Adler Al, Neil HAW, Matthews DR, Manley SE, Cull CA, Hadden D, Turner RC, Holman RR: Association of glycaemia with macrovascular and microvascular complications of type 2 diabetes (UKPDS 35): prospective observational study. BMJ 2000, 321(7258):405-412.

26. AlHW: Diabetes Prevalence in Australia: An Assessment of National Data Sources Canberra: Australian Institute of Health and Welfare; 2009.

27. Johnson JA, Coons SJ: Comparison of the EQ-5D and SF-12 in an adult U. S. sample. Quality Life Res 1998, 7(2):155-166.

28. David M, Ware $R$, Donald M, Alati R: Assessing generalisability through the use of disease registers: findings from a diabetes cohort study. $B M$ J Open 2011, 1.

29. National Health and Medical Research Council: Dietary guidelines for Australian adults.Edited by: NHMRC. Canberra: National Health and Medical Research Council; 2003:

30. AlHW: Statistics on Drug Use in Australia 2006. Canberra: Australian Institute of Health and Welfare; 2007.

31. National Health and Medical Research Council: Australian guidelines to reduce health risks from drinking alcohol. Canberra: Commonwealth of Australia; 2009

32. AlHW: The active Australia survey. Canberra: Australian Institute of Health and Welfare; 2003.

33. Commonwealth Department of Health and Aged Care: National physical activity guidelines for Australians. Canberra: Department of Health and Aged Care; 1999.

34. WHO: Obesity: Preventing and Managing the Global Epidemic Geneva: World Health Organization; 2000.

35. Rabin R, de Charro F: EQ-5D: a measure of health status from the EuroQol group. Annals Med 2001, 33(5):337-343.

36. Bradley C, Todd C, Gorton T, Symonds E, Martin A, Plowright R: The development of an individualised questionnaire measure of perceived impact of diabetes on quality of life: the ADDQoL. Quality Life Res 1999, 8:79-91.

37. Bradley C, Speight J: Patient perceptions of diabetes and diabetes therapy: assessing quality of life. Diabetes Metab Res Rev 2002, 18:564-S69.

38. Hibbard JH, Stockard J, Mahoney ER, Tusler M: Development of the Patient Activation Measure (PAM): conceptualizing and measuring activation in patients and consumers. Health Serv Res 2004, 39(4):1005-1026.

39. Toobert DJ, Glasgow RE: Assessing diabetes self-management: the summary of diabetes self-care activities questionnaire. In Handbook of Psychology and Diabetes: A Guide to Psychological Measurment in Diabetes Research and Practice. Edited by: Bradley C. Chur, Switzerland: Harwood Academic; 1994:351-375. 
40. Glasgow RE, Strycker LA, Toobert DJ, Eakin E: A social-ecologic approach to assessing support for disease self-management: the chronic illness resources survey. J Behavioral Med 2000, 23(6):559-583.

41. Glasgow RE, Wagner EH, Schaefer J, Mahoney LD, Reid RJ, Greene SA: Development and validation of the Patient Assessment of Chronic Illness Care (PACIC). Med Care 2005, 43(5):436-444.

42. Diabetes Australia: Diabetes management in general practice: guidelines for Type 2 diabetes. Canberra: Diabetes Australia; 2007.

43. Radloff LS: The CES-D scale: a self-report depression scale for research in the general population. Appl Psychol Meas 1977, 1(3):385-401.

44. Scheier MF, Carver CS, Bridges MW: Distinguishing optimism from neuroticism (and trait anxiety, self-mastery, and self-esteem): a reevaluation of the life orientation test. J Personality Social Psychology 1994, 67:1063-1078

45. Mitchell P, Powell L, Blumenthal J, Norten J, Ironson G, Pitula CR, Froelicher ES, Czajkowski S, Youngblood M, Huber M, et al: A short social support measure for patients recovering from myocardial infarction: the ENRICHD social support inventory. J Cardiopulmonary Rehabilitation 2003, 23(6):398-403.

46. ABS: National health survey: users' guide-electronic publication, Australia 2004-05, Cat. No. 4363.0.55.001. Canberra: Australian Bureau of Statistics; 2006.

47. Rehm J, Greenfield TK, Walsh G, Xie X, Robson L, Single E: Assessment methods for alcohol consumption, prevalence of high risk drinking and harm: a sensitivity analysis. Int J Epidemiol 1999, 28:219-244.

48. Cheung K, Oemar M, Oppe M, Rabin R: EQ-5D User Guide: Basic Information on how to Use the EQ-5D. Version 2.0 Rotterdam: EuroQoL Group; 2009

49. Wagner EH: Chronic disease management: what will it take to improve care for chronic illness? Eff Clin Pract 1998, 1(1):2-4.

50. Bradley C: Importance of differentiating health status from quality of life. Lancet 2001, 357(9249):7-8.

51. Tsuchiya A, Brazier J, Roberts J: Comparison of valuation methods used to generate the EQ-5D and the SF-6D value sets. J Health Econ 2006, 25(2):334-346.

52. Speight J, Reaney MD, Barnard KD: Not all roads lead to Rome-a review of quality of life measurement in adults with diabetes. Diabetic Med 2009, 26(4):315-327.

53. El Achhab Y, Nejjari C, Chikri M, Lyoussi B: Disease-specific health-related quality of life instruments among adults diabetic: a systematic review. Diabetes Res Clin Pract 2008, 80(2):171-184.

54. Garratt AM, Schmidt L, Fitzpatrick R: Patient-assessed health outcome measures for diabetes: a structured review. Diabetic Med 2002, 19(1):1-11.

55. Ostini R, Dower J, Donald M: The Audit of Diabetes Dependent Quality of Life 19 (ADDQoL): feasibility, reliability and validity in a population based sample of Australian adults. Quality life Res 2011, DOl:10.1007/ s11136-011-0043-0.

56. Wallihan DB, Stump TE, Callahan CM: accuracy of self-reported health services use and patterns of care among urban older adults. Med Care 1999, 37(7):662-670.

57. Roberts RO, Bergstralh EJ, Schmidt L, Jacobsen SJ: Comparison of selfreported and medical record health care utilization measures. $J$ Clin Epidemiol 1996, 49(9):989-995.

58. Martin LM, Leff M, Calonge N, Garrett C, Nelson DE: Validation of selfreported chronic conditions and health services in a managed care population. Am J Preventive Med 2000, 18(3):215-218.

59. Bergmann MM, Byers T, Freedman DS, Mokdad A: Validity of self-reported diagnoses leading to hospitalization: a comparison of self-reports with hospital records in a prospective study of American adults. Am J Epidemiol 1998, 147(10):969-977.

60. Harwell TS, Dettori N, McDowall JM, Quesenberry K, Priest L, Butcher MK, Flook BN, Helgerson SD, Gohdes D: Do persons with diabetes know their (AIC) number? Diabetes Educator 2002, 28(1):99-105.

61. Fowles J, Rosheim K, Fowler E, Craft C, Arrichiello L: The validity of selfreported diabetes quality of care measures. Int J Qual Health Care 1999, 11(5):407-412

62. Dunstan DW, Zimmet PZ, Welborn TA, Cameron AJ, Shaw J, de Courten M, Jolley D, McCarty DJ: The Australian diabetes, obesity and lifestyle study (AusDiab)-methods and response rates. Diabetes Res Clin Pract 2002 57(2):119-129

63. Nohr EA, Frydenberg M, Henriksen TB, Olsen J: Does low participation in cohort studies induce bias? Epidemiology 2006, 17(4):413-418.
64. Edwards P, Roberts I, Clark M, Di Guiseppi C, Pratap S, Wentz R, Kwan I: Increasing response rates to postal questionnaires: systematic review. $\mathrm{Br}$ Med J 2002, 324:1183-1191.

65. VanGeest J, Wynia M, Cummins D, Wilson I: Effects of different money incentives on the return rate of a national mail survey of physicians. Med Care 2001, 39:197-201.

66. Australian Government: Families in Australia: 2008. Cabinet DotPMa. Canberra; 2008.

67. Connolly V, Unwin N, Sherriff P, Bilous R, Kelly W: Diabetes prevalence and socioeconomic status: a population based study showing increased prevalence of type 2 diabetes mellitus in deprived areas. J Epidemiol Community Health 2000, 54(3):173-177.

68. Geiss $L S$, Cowie CC: Type 2 diabetes and persons at high risk of diabetes. Diabetes Public Health 2010, 1:15-33.

69. Daniel M, Rowley KG, McDermott R, Mylvaganam A, O'Dea K: Diabetes incidence in an Australian aboriginal population. An 8-year follow-up study. Diabetes Care 1999, 22(12):1993-1998.

70. Australian Bureau of Statistics: Population distribution, aboriginal and torres strait islander Australians, 2006. Canberra: Australian Bureau of Statistics; 2007.

71. AlHW: Diabetes: Australian Facts 2008 Canberra: AlHW; 2008.

72. Klein S, Sheard NF, Pi-Sunyer X, Daly A, Wylie-Rosett J, Kulkarni K, Clark NG Weight management through lifestyle modification for the prevention and management of type 2 diabetes: Rationale and strategies. Diabetes Care 2004, 27(8):2067-2073

73. Nathan DM, Buse JB, Davidson MB, Heine RJ, Holman RR, Sherwin R, Zinman B: Management of hyperglycemia in type 2 diabetes: a consensus algorithm for the initiation and adjustment of therapy. Diabetes Care 2006, 29(8):1963-1972.

74. Morrato EH, Hill JO, Wyatt HR, Ghushchyan V, Sullivan PW: Physical activity in U.S. adults with diabetes and at risk for developing diabetes, 2003. Diabetes Care 2007, 30(2):203-209.

75. Magliano DJ, Barr ELM, Zimmet PZ, Cameron AJ, Dunstan DW, Colagiuri S, Jolley D, Owen N, Phillips P, Tapp RJ, et al: Glucose indices, health behaviors, and incidence of diabetes in Australia: the Australian diabetes, obesity and lifestyle study. Diabetes Care 2008, 31(2):267-272.

76. Vandelanotte C, Duncan MJ, Caperchione C, Hanley C, Mummery WK: Physical activity trends in Queensland (2002 to 2008): are women becoming more active than men? Aust New Zealand J Public Health 2010, 34(3):248-254

\section{Pre-publication history}

The pre-publication history for this paper can be accessed here: http://www.biomedcentral.com/1471-2458/12/8/prepub

doi:10.1186/1471-2458-12-8

Cite this article as: Donald et al: Living with diabetes: rationale, study design and baseline characteristics for an Australian prospective cohort study. BMC Public Health 2012 12:8.

\section{Submit your next manuscript to BioMed Central and take full advantage of:}

- Convenient online submission

- Thorough peer review

- No space constraints or color figure charges

- Immediate publication on acceptance

- Inclusion in PubMed, CAS, Scopus and Google Scholar

- Research which is freely available for redistribution 